\title{
Decolorization of Methylene Blue and Malachite Green by Immobilized Desmodesmus sp. Isolated from North Jordan
}

\author{
Abdullah T. Al-Fawwaz and Mufida Abdullah
}

\begin{abstract}
The increasing presence of dyes represents a major environmental toxicity hazard; therefore, finding and development of new methods for dye removal from waste water has generated significant interest. Chemical, physical and electrochemical methods have limited use as they have many disadvantages compared with the biological methods. The aim of this study was to test the effects of immobilization and some culture conditions on decolorization of methylene blue and malachite green by Desmodesmus sp. isolated from local environment. Decolorization of dyes by free and immobilized Desmodesmus sp. was tested by monitoring the decrease in absorbance of each dye under different culture condition such as incubation time and dye concentrations. The results showed that the maximum decolorization of both dyes with immobilized algae after 6 days at $20 \mathrm{mg}^{-\mathrm{L}^{-1}}$ of dye concentration with $98.6 \%$. The results showed that there was decolorization ability of immobilized Desmodesmus sp. against the dyes compared with free one. The analysis of the results showed that there was different factors affected decolorization ability.
\end{abstract}

Index Terms-Algae, decolorization, dyes, immobilization.

\section{INTRODUCTION}

The estimated number of the synthetic dyes on the market are more than 100,000, with annual production over 700,000 tons worldwide. These dyes are used in paper industry, textile, cosmetics, food and pharmaceutical industries. Furthermore, some dyes are dangerous to cells and living organisms due to their potential mutagenicity, toxicity and carcinogenicity [1]-[3].

Methylene blue (MB) and malachite green (MG) are widely used dyes. Both dyes have been reported for their negative impact on living cells and organisms. The oral median lethal dose $\left(\mathrm{LD}_{50}\right)$ of methylene blue and malachite green in rats has been estimated as 1180 and $275 \mathrm{mg} \cdot \mathrm{kg}^{-1}$, respectively [4], [5]. It was also found that at low and moderate doses of MB arterial blood pressure increased, whereas at high doses it will worsen systemic hypotension, mycocardardial depression and hypertension after endotoxemia [6]. MG has been reported to cause carcinogenesis, mutagenesis, chromosomal fracture, teratogenicity, and respiratory toxicity [7], [8].

Conventional methods such as chemical precipitation, chemical coagulation, chemical oxidation and adsorption have limited use as they are cost-intensive and generate large amounts of solid waste, resulting in higher pollution potential than the effluents [9]-[11], and these methods are usually

Manuscript received August 14, 2014; revised May 12, 2015.

The authors are with Al al-Bayt University, Mafraq 25113, Jordan (e-mail: al_fawwaz@aabu.edu.jo,mufidak101282@yahoo.com). effective only if the effluent volume is small [12]. In such cases, biological processes are good alternatives for dye removal [9], [13].

In recent years, several studies have focused on some microorganisms for the removal of synthetic dyes from aqueous solutions, wastewater and industrial effluents. The process is relatively inexpensive, the running costs are low and the end products of complete mineralization are not toxic [9], [14]. Different microorganisms have been tested for the decolorization dyes such as heterotrophic bacteria, for instance Escherichia coli [15] and Pseudomonas luteola [16]; molds, for example Aspergillus niger [17], Aspergillus terricola [18]; yeasts, like Saccharomyces cerevisiae, Candida tropicalis, C. lipolytica [19]; and algae, like Spirogyra species [20], Lemna minuscule [21], and Cosmarium sp. [9], [22]. Among all these potential biosorbents, algae have received considerable interest because they are locally available and cost effective.

However, few studies have investigated the efficiency of fresh algae to decolorize dye effluents. The objectives of this study were to investigate the effects of immobilization and some cultural conditions (incubation time and dye concentration) to decolorize methylene blue and malachite green dyes using fresh green algae (Desmodesmus sp.) as biosorbent.

\section{MATERIALS AND METHODS}

\section{A. Microalgal Culture}

Green microalgae were obtained from the banks of water stream originating from water spring located at Ajloun area in north Jordan in May, 2012 (location: 32²4'02.86"N, $\left.35^{\circ} 41^{\prime} 37.38^{\prime \prime} \mathrm{E}\right)$. The samples were collected in clean and sterile glass bottles and transferred to the laboratory for isolation.

\section{B. Isolation, Cultivation and Classification of Microalgae}

Green microalgal samples were cultivated in flasks (1L) containing $600 \mathrm{~mL}$ Bold Basal Medium (BBM). Isolation of algal colonies was carried out by a series of subcultures on BBM agar plates. Once algal colonies were separated, a pure culture was prepared and microscopically examined. Pure strains were then cultivated on BBM agar slants and stored in refrigerator. Routine cultivation was carried out at $25^{\circ} \mathrm{C}$ under light intensity of $20.25 \mu \mathrm{E} \mathrm{m}^{-2} \mathrm{~S}^{-1}$ for 15 days. A pure culture was chosen and was identified by University of Texas culture collection, Utex CC, USA as Desmodesmus sp.

\section{Preparation of Dye Aqueous Solutions}

The dyes used in all the experiments were methylene blue 
(MB) and malachite green (MG). The dyes and their chemical structures (Fig. 1) and properties are listed below,

1) Methylene blue: Color index; C.I (52015), Maximum wavelength; $\lambda \max 660 \mathrm{~nm}$, Molecular weight, MW, 319.9 g.mol ${ }^{-1}$, and Molecular formula $\left(\mathrm{C}_{16} \mathrm{H}_{18} \mathrm{~N}_{3} \mathrm{SCl}\right)$.

2) Malachite green: Color index; C.I (42000), Maximum wavelength; $\lambda \max 619 \mathrm{~nm}$, Molecular weight, MW, 365 g.mol ${ }^{-1}$, and Molecular formula $\left(\mathrm{C}_{23} \mathrm{H}_{25} \mathrm{~N}_{2} \mathrm{Cl}\right)$ [8].<smiles>CN=c1ccc2nc3ccc(N(C)C)cc3sc-2c1</smiles>

a)

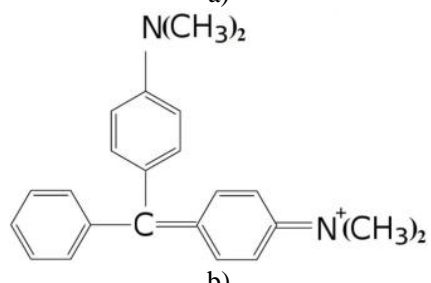

b)

Fig. 1. Chemical structures of methylene blue a) and malachite green b) dyes used in this study.

\section{Experimental Setup}

Decolorization of $\mathrm{MB}$ and $\mathrm{MG}$ dyes was determined spectrophotometrically. The absorbance was measured with spectrophotometer (UV/Vis spectrophotometer WPA light wave S2000) at two different wavelengths depending on the dye: $660 \mathrm{~nm}$ for abiotic control solutions or free and immobilized dye aqueous Solutions containing MB, and 619 $\mathrm{nm}$ for abiotic control solutions or free and immobilized dye aqueous Solutions containing MG. Microalgal cells and alginate beads were removed from cultures by centrifugation at $6700 \mathrm{rpm}$ for $10 \mathrm{~min}$ and the absorbance of cell-free supernatant was measured at the corresponding wavelength. The experiments were incubated at $25^{\circ} \mathrm{C}$ and inoculums concentration of $0.25 \mathrm{~g} . \mathrm{L}^{-1}$. The initial solution $\mathrm{pH}$ was 6.8 for both dyes. The percentage of dye removed was calculated using the following equation:

$$
\operatorname{Removal}(\%)=\frac{\left(C_{i}-C_{f}\right)}{C_{i}} \times 100
$$

where $C_{i}$ is the initial concentration of dye $\left(\mathrm{mg} . \mathrm{L}^{-1}\right)$ and $C_{f}$ is the concentration of dye after a period of time. Decolorization was determined based on an absorbance calibration curve of known standard solutions.

In immobilization experiments the difference in dye concentration between blank beads and beads with microalgae were considered, and decolorization percentage of immobilization experiments will be as the following equation:

$$
=\frac{\left(C_{i}-C_{t}\right)-\left(C_{i}-C_{b l a n k}\right)}{C_{i}} \times 100
$$

where $C_{t}$ is the concentration of dyes after decolorization by algal beads, $C_{\text {blank }}$ is the concentration of dyes after decolorization by blank beads (mg. $\left.\mathrm{L}^{-1}\right)$ after a period of time.

\section{E. Immobilization of Microalgae (Desmodesmus sp.)}

Immobilization of algae cells in sodium alginate solution were prepared by the method described by [23]. To immobilize the algae in alginate matrix via entrapment, 3\% sodium alginate solution was mixed with 0.25 g.L ${ }^{-1}$ dry weight algal suspension to give $2: 1 \mathrm{v}: \mathrm{v}$ alginate to algal suspension ratio. To create blank alginate beads (without algae), 3\% sodium alginate was mixed with deionized water. The 3\% alginate-algae mixture or alginate suspension was then introduced drop wise $\left(8-10 \mathrm{~cm}\right.$ away of $\mathrm{CaCl}_{2}$ solution) into $0.03 \mathrm{M} \mathrm{CaCl}_{2}$ to produce the beads. The beads started to harden almost immediately when dropped into the $\mathrm{CaCl}_{2}$ solution and were left in the solution overnight to fully harden. The beads were then washed three times in deionized water and stored at $4{ }^{\circ} \mathrm{C}$ if not used immediately. Fig. 2 illustrates the beads produced.

Experiments were conducted in triplicates and the experimental data represents the mean of the \pm standard deviations.

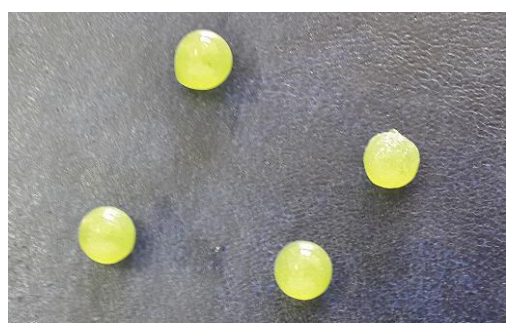

Fig. 2. Photograph of beads produced for decolorization process.

\section{RESULTS}

Contact time is an important parameter to determine the optimum time of decolorization process. Decolorization studies were carried out for 8 days and it was observed that the removal of $\mathrm{MB}$ was found to increase rapidly by free and immobilized algae in the first 2 and 4 days, respectively (Fig. 3). MB removal reached 64.4 and $98.4 \%$ by free and immobilized algae, respectively. The same trend was observed in both states (free and immobilized); MB removal efficiency became stable after the first 4 days for immobilized treatment and after the first 2 days for free treatment.

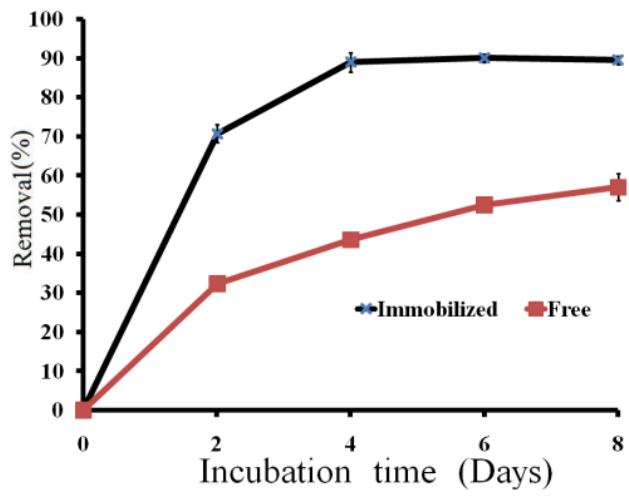

Fig. 3. Effects of Incubation time on methylene blue removal efficiency by free and Immobilized Desmodesmus sp.

The effect of contact time on the amount of malachite green by free and Immobilized Desmodesmus sp. was investigated. Fig. 4 shows that the best removal efficiency of M.G was after 4 days with $88.9 \%$ when Desmodesmus sp. in alginate beads 
was used as biosorbent. Free state of Desmodesmus sp. shows less M.G removal efficiency compared with immobilized one, the best removal efficiency of M.G was after 8 days with $57.4 \%$ when Desmodesmus sp. was used in the free state.

For both dyes immobilized Desmodesmus sp. shows the best decolorization efficiency compared with the free state and it happen in the 2-4 days of contact.

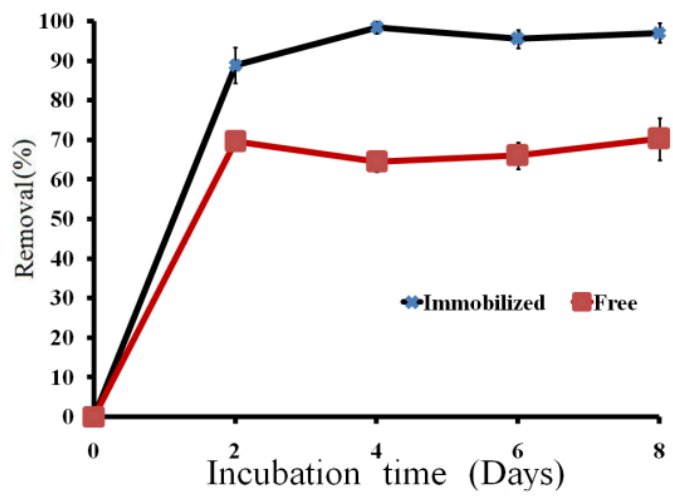

Fig. 4. Effects of Incubation time (days) on malachite green removal efficiency by free and Immobilized Desmodesmus sp.

The effect of immobilization with initial dye concentration of both dyes was also investigated (Fig. 5 and Fig. 6). As noted in Fig. 5 methylene blue removal efficiency decreases as dye concentration increased and the best decolorization of methylene blue was at $5 \mathrm{mg} . \mathrm{L}^{-1}$ with $95.7 \%$ compared with $71.6 \%$ at $20 \mathrm{mg} . \mathrm{L}^{-1}$ when Desmodesmus sp. was used in immobilized state. The same trend was observed when Desmodesmus sp. was used in the free state with 97.5 and $56.8 \%$ at 5 and $20 \mathrm{mg} . \mathrm{L}^{-1}$, respectively.

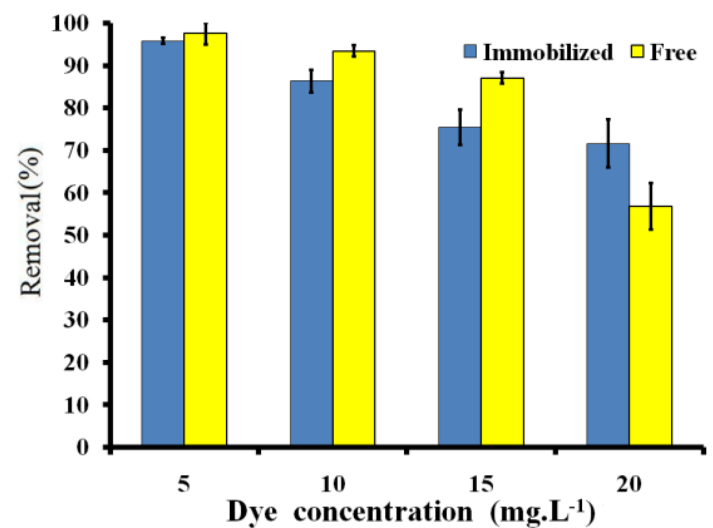

Fig. 5. Effects of dye concentration (mg. $\mathrm{L}^{-1}$ ) on methylene blue removal efficiency by free and Immobilized Desmodesmus sp.

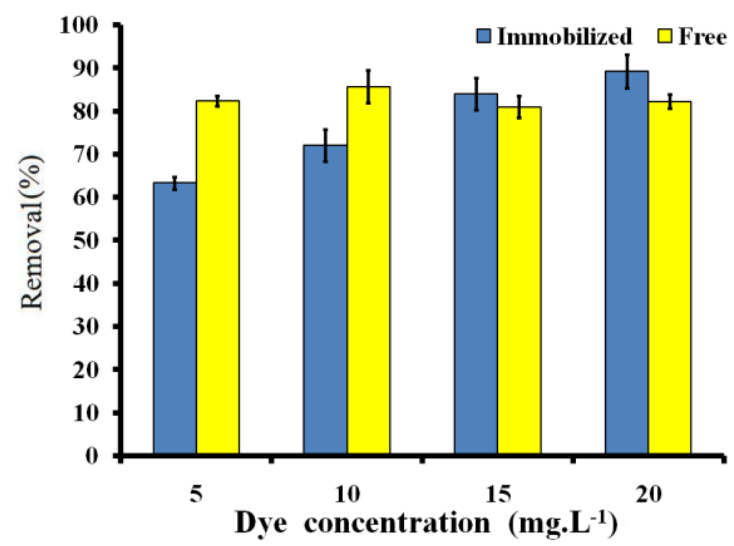

Fig. 6. Effects of dye concentration $\left(\mathrm{mg} . \mathrm{L}^{-1}\right)$ on malachite green removal efficiency by free and immobilized Desmodesmus sp.
Results obtained in Fig. 6 shows that dye removal efficiency slightly increases as initial malachite green increased when Desmodesmus sp. was used in immobilized state and the maximum removal efficiency was $89.1 \%$ at $20 \mathrm{mg} . \mathrm{L}^{-1}$ compared with $63.2 \%$ at $5 \mathrm{mg} . \mathrm{L}^{-1}$. There was no significant difference in decolorization efficiency of malachite green when Desmodesmus sp. was used as free state.

Fig. 7 shows the different treatments in immobilization experiments, there was slightly decrease in MB color after 6 days when blank beads was used as biosorbents (Fig. 7B) compared with clear solution when immobilized Desmodesmus sp. was used (Fig. 7C).

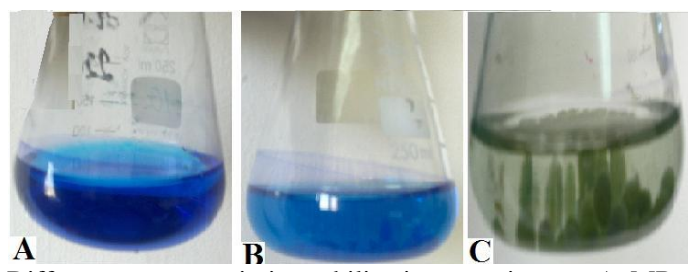

Fig. 7. Different treatments in immobilization experiments; A: MB control, B: MB with blank beads, $\mathrm{C}$ : MB with immobilized algae, after 6 days of incubation.

\section{DISCUSSION}

Dyes are widely used in many fields, for instance in textile industry and in biology in a number of biological staining procedures. Methylene blue and malachite green are good examples which are used in many fields and also have a wide variety of toxicological effects [6], [7], [24]. Removal of these dyes from wastewater and contaminated sites is of major concern due to biological, environmental, and aesthetic reasons. Therefore, several studies were conducted to decolorize such these dyes from the environment [25], [26], [22]. In this study, one strains of green microalgae were isolated, Desmodesmus sp. from water stream habitats. The ability of Desmodesmus strain to remove MB and MG from aqueous solutions in both states (free and immobilized) was examined. Free and immobilized states of Desmodesmus were able to decolorize methylene blue and malachite green from aqueous solutions with high capacity reaches $98.3 \%$ dye removal. However, decolorization was dependent on several factors including initial dye concentration, contact time and immobilization.

Generally, cell walls of green algae are made up of cellulose as the main structural polysaccharide, lipids, and proteins. Extracellular polymers of algal cell wall consist of surface functional groups such as hydroxyl, carbonyl and carboxyl groups, which provide binding sites and enhance sorption of the dye molecules onto the surface of the polymer during decolorization process[27], [28].

In the present investigation, Desmodesmus sp. significantly reduced $\mathrm{MB}$ and $\mathrm{MG}$ color from dye aqueous solutions in both free and immobilized conditions. Both conditions were relatively rapid in $\mathrm{MB}$ and $\mathrm{MG}$ dye removal. More than $70.7 \%$ removal of color was recorded in all the treatment with the incubation period of 8 days; though the immobilized cells performed well over free cells (Fig. 3 and Fig. 4). The highest removal percentage was observed in the first 2 days. The results show that the decolorization of dyes was increased 
with time up to 2-4 days. However, the rate of dye decolorization was quite slow after day 4. One possible explanation is that all binding sites became occupied on the algal biomass after the first $\mathrm{d}$ days, which exerted elevated toxicity on the algal biomass. The time dependant experiment showed that the initial two hour was significant for dyes decolorization and results were agreed by earlier workers [26], [29], [30]. In both condition, experiments were performed until 2-4 days min beyond which the removal rate of the microalgae became stable. The immobilized beads used with both dyes proved to be more efficient on dye decolorization than free biomass (Fig. 3 and Fig. 4). This observation suggested that decolorization increased with increasing time as agreed by previous worker [31]. They stated that the maximum time is (not exceeding seven days) an ideal way to reduce the color from the dye wastewater. Reference [32] reported a $95.4 \% \mathrm{MG}$ decolorization in 72 hours using the filamentous fungus Acremonium kiliense. In other study by [33], Aspergillus flavus and Alternaria solani were able of MG removal with a decolrization percentage of $97.43 \%$ and $96.91 \%$, respectively, in 6 days.

Immobilization of algae as beads is a very efficient method of cell entrapment because it allow high cell loading and are translucent to light. Also it can be used many times in photobioreactors [25], [26]. Alginate is the most frequent polymer used for algal immobilization. Many authors reported that microalgae is a common and effective species for the immobilization and adsorption purposes [34]-[36], [26]. The biosorption capacity of algae is attributed to their relatively high surface area and high binding affinity [37]. The decolorization of present study (Desmodesmus sp.; $95.8 \%$ ) were quietly high compared to other workers [38] has been dealt with marine species (Lyngbya sp.; 46.3\%). Studies have adequately verified cell viability in the alginate matrix [39]. In a freely suspended algal treatment system, the removal efficiency is often directly related to the cell mass. Increasing the algal biomass would improve the removal efficiency and shorten the retention time [26], [40].

The highest removal capacity was observed at initial dye concentration $5 \mathrm{mg} . \mathrm{L}^{-1}$ for $\mathrm{MB}$ dyes and for both conditions, even though a higher concentration $\left(20 \mathrm{mg} . \mathrm{L}^{-1}\right)$ was tested. As the dye concentration increased beyond $5 \mathrm{mg} . \mathrm{L}^{-1}$, the removal capacity decreased. This can be explained by the binding capacity of the algal biomass and/or the toxicity of dyes. High surface area and high biding affinity of some functional groups as hydroxyl, carboxyl, amino, and phosphate groups on the surface of algae are considered to be responsible for sequestration of contaminants from wastewater [22]. In Fig. 6, the removal percentage of immobilized algae increased with increasing concentration and this may be due to alginate beads which protect algal biomass. On the contrary, decolorization of MG by free Desmodesmus sp. was not affected by increasing dye concentration and one possible explanation is that algal cells in the flasks were free which provide a higher surface area of algae and therefore higher number of binding sites leading to higher removal capacity. Higher removal capacity may be due to electrostatic interactions between the negatively functional groups on the algal surface and the positively charged methylene blue and malachite green dyes in the flasks [8].

\section{CONCLUSIONS AND RECOMMENDATIONS}

From the above discussion it is cleared that Desmodesmus sp. in both free and immobilized condition can successfully be used as biosorbent to decolorize and reduce the effects of $\mathrm{MB}$ and MG dyes. Immobilized beads were more efficient in decolorization than the free biomass in all treatments. Contact time and initial dye concentration affect decolorization process. According to the previous results this study highly recommends using Desmodesmus sp. in other bioremediation applications for pollutant removal.

\section{REFERENCES}

[1] S. Rajeswari, C. Namasivayam, and K. Kadirvelu, "Orange peel as an adsorbent in the removal of acid violet 17 (acid dye) from aqueous solutions," Waste Management, vol. 21, no. 1, pp. 105-110, May 2001.

[2] K. Kadirvelu, M. Kavipriya, C. Karthika, M. Radhika, N. Vennilamani, and S. Pattabhi, "Utilization of various agricultural wastes for activated carbon preparation and application for the removal of dyes and metal ions from aqueous solution," Bioresource Technology, vol 87, no. 1, pp. 129-132, March 2003.

[3] A. Pavko, "Fungal decolourization and degradation of synthetic dyes," in Waste Water - Treatment and Reutilization, F. S. García, Ed., 2011, pp. $65-88$.

[4] S. Clemmensen, J. C. Jensen, N. J. Jensen, O. A. Meyer, K. Olsen, and G. Würtzen, "Toxicological studies on malachite green: A triphenylmethane dye," Archives of Toxicology, vol. 56, pp. 43-45, 1984.

[5] C. Seif, F. J. M. Portillo, D. K. Osmonov, G. Böhler, C. Horst, J. Leissner, R. Hohenfellner, K. P. Juenemann, and P. M. Braun, "Methylene blue staining for nerve-sparing operative procedures: An animal model," Urology, vol. 63, pp. 1205-1208, June 2004.

[6] H. Zhang, P. Rogiers, J. C. Preiser, H. Spapen, P. Manikis, G. Metz, and J. L. Vincent, "Effects of methylene blue on oxygen availability and regional blood flow during endotoxic shock," Critical Care Medicine, vol. 10, pp. 1711-1721, October 1995.

[7] S. Srivastava, R. Sinha, and D. Roy, "Toxicological effects of malachite green," Aquatic Toxicology, vol. 66, pp. 319-329, September 2004.

[8] A. T. Al-Fawwaz and J. H. Jacob, "Removal of methylene blue and malachite green from aqueous solution by Chlorella and Chlamydomonas species isolated from a thermal spring environment," International Journal of Integrative Biology, vol. 12, no.1, pp. 36-41, 2011.

[9] N. Daneshvar, M. Ayazloo, A. R. Khataee, and M. Pourhassan, "Biological decolorization of dye solution containing malachite green by microalgae Cosmarium sp," Bioresource Technology, vol. 98, no. 6, pp. 1-7, April 2007.

[10] K. V. Kumar, V. Ramamurthi, and S. Sivanesan, "Biosorption of malachite a green cationic dye onto Pithophora sp., a fresh water algae," Dyes Pigments, vol. 69, pp. 74-79, 2006.

[11] C. Kumara, P. Mongollaa, J. Josepha, and V. Sarmab, "Decolorization and biodegradation of triphenylmethane dye, brilliant green, by Aspergillus sp. isolated from Ladakh, India," Elsevier Journal, vol. 47, pp. 1388-1394, 2012.

[12] T. Robinson, G. McMullan, R. Marchan, and P. Nigam, "Remediation of dyes in textile effluent: A critical review on current treatment technologies with a proposed alternative," Bioresour Technololgy, vol. 77, pp. 247-55, 2001.

[13] V. Vilar, C. Botelho, and R. Boaventura, "Methylene blue adsorption by algal biomass based materials: Biosorbents characterization and process behavior," Journal of Hazardous Materials, vol. 147, pp. 120-132, August 2007

[14] E. Forgacs, T. Cserha, and G. Orosb, "Removal of synthetic dyes from wastewaters: A review," Elsevier Journal, vol. 67, pp. 953-972, 2004

[15] J. S. Chang and T. S. Kuo, "Kinetics of bacterial decolorization of azo dye with Escherichia coli $\mathrm{NO}_{3}$," Bioresource Technology, vol. 75, pp. 107-111, 2000.

[16] J. S. Chang et al., "Kinetic characteristics of bacterial azo-dye decolorization by Pseudomonas luteola," Water Research, vol. 35, no. 12, pp. 2841-2850, August 2001

[17] Y. Z. Fu and T. Viraraghavan, "Removal of a dye from aqueous solution by the fungus Aspergillus niger," Water Quality Research Journal of Canada, vol. 35, pp. 95-111, 2000. 
[18] N. Saikia and M. Gopal, "Biodegradation of b-Cyfluthrin by fungi," Journal of Agricultural and Food Chemistry, vol. 52, pp. 220-223, 2004.

[19] Z. Aksu and G. Donmez, "A comparative study on the biosorption characteristics of some yeasts for remazol blue reactive dye," Chemospher, vol. 50, pp. 1075-83, 2003.

[20] V. K. Gupta, A. Rastogi, V. K. Saini, and N. Jain, "Biosorption of copper (II) from aqueous solutions by Spirogyra species," Journal of Colloid and Interface Science, vol. 296, pp. 59-63, 2006.

[21] L. T. Valderama, C. M. D. Campo, L. T. Valderrama, C. M. D. Campo, C. M. Rodriguez, L. E. de-Bashan, and Y. Bashan, "Treatment of recalcitrant wastewater from ethanol and citric acid production using the microalga Chlorella vulgaris and the macrophyte Lemna minuscula," Water Research, vol. 36, pp. 4185-4192, March 2002.

[22] A. Srinivasan and T. Viraraghavan, "Decolorization of dye wastewaters by biosorbents: A review," Journal of Environmental Managemen, vol. 91, pp. 1915-1929, 2010.

[23] Y. C. Chen, "Immobilized microalga Scenedesmus quadricauda (chlorophyta, chlorococcales) for long-term storage and for application for water quality control in fish culture," Aquaculture, vol. 195, pp. $71-80,2001$.

[24] K. Gillman, "CNS toxicity involving methylene blue: The exemplar for understanding and predicting drug interactions that precipitate serotonin toxicity," Journal of Psychopharmacology, vol. 25, pp. 429-436, 2011.

[25] S. Vijayakumar and C. Manoharan, "Treatment of dye industry effluent using free and immobilized cyanobacteria," J. Bioremed. Biodeg., vol. 3, pp. 165-170, 2012.

[26] S. D. Kumar, P. Santhanam, R. Nandakumar, S. Ananth, B. Balaji Prasath, A. Shenbaga Devi, S. Jeyanthi, T. Jayalakshmi, and P. Ananthi, "Preliminary study on the dye removal efficacy of immobilized marine and freshwater microalgal beads from textile wastewater," African Journal of biotechnology, vol. 13, no. 22, pp. 2288-2294, 2014.

[27] O. Z. Murat, E. L. Dietrich, H. Mohammed, and A. P. George, "Cellular and molecular actions of methylene blue in the nervous system," Medicinal Research Reviews, vol. 31, no.1, pp. 93-117, September 2010.

[28] W. T. Tsai and H. R. Chen, "Removal of malachite green from aqueous solution using low-cost Chlorella-based biomass," Journal of Hazardous Materials, vol. 175, pp. 844-849, 2010.

[29] A. A. Khan and Q. Husain, "Decolorization and removal of textile and non-textile dyes from polluted wastewater and dyeing effluent by using potato (Solanum Tuberosum) soluble and immobilized polyphenol oxidase," Biores. Technol., vol. 98, pp. 1012-1019, 2007.

[30] G. Arabaci and A. Usluoglu, "The enzymatic decolorization of textile dyes by the immobilized polyphenol oxidase from quince leaves," $S C I$. World J., pp. 1-5. 2014.

[31] K. Saraswathi and S. Balakumar, "Biodecolorization of azodye (pigmented red 208) using Bacillus firmus and Bacillus laterosporus," J. Biosci. Tech., vol. 1, pp. 1-7, 2009.
[32] A. S. Youssef, M. F. El-Sherif, and S. A. El-Assar, "Studies on the decolorization of malachite green by the local isolate Acremonium kiliense," Biotechnology, vol. 7, pp. 213-223, 2008.

[33] H. Ali, W. Ahmad, and T. Haq, "Decolorization and degradation of malachite green by Aspergillus flavus and Alternaria solani," African Journal of Biotechnology, vol. 8, pp. 1574-1576, April 2009.

[34] N. Tam, P. Lau, and Y. Wong, "Wastewater inorganic N and P removal by immobilized Chlorella vulgaris," Water Sci. Tech., vol. 30, pp 369-374, 1994.

[35] P. S. Lau, N. Tam, and Y. Wong "Operational optimization of batch wise nutrient removal from wastewater by carrageenan immobilized Chlorella vulgaris," Water Sci. Technol., vol. 38, pp. 192-198, 1998.

[36] K. S. Dinesh, P. Santhanam, T. Jayalakshmi, R. Nandakumar, S Ananth, D. A. Shenbaga, and P. B. Balaji, "Optimization of $\mathrm{pH}$ and retention time on the removal of nutrients and heavy metal (zinc) using immobilized marine microalga Chlorella Marina," J. Biolog. Sci., vol. 13, pp. 400-405. 2013

[37] G. Donmez and Z. Aksu, "Removal of chromium (VI) from saline wastewaters by Dunaliellaa species," Process Biochem., vol. 38, pp. 751-762, 2002.

[38] S. Henciya, S. Murali, and P. Malliga, "Decolorization of textile dye effluent by marine cyanobacterium Lyngbya sp. BDU 9001 with coir pith," Int. J. Environ. Sci., vol. 3, pp. 1909-1918, 2013.

[39] C. Vilchez, I. Garabayo, E. Marckvichea, F. Gavan, and R. Leon "Studies on the suitability of alginate-entrapped Chlamydomonas reinhardtii cells for sustaining nitrate consumption process," Biores. Tech., vol. 78, pp. 55-61, 2001.

[40] P. S. Lau, N. Tam, and Y. Wong "Effect of algal density on nutrient removal from primary settled wastewater," Environ. Pollut., vol. 89, pp. 59-66, 1995.

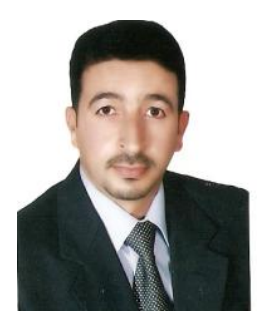

Abdullah T. Al-Fawwaz was born in Jordan in 1974. $\mathrm{He}$ is a full-time faculty of $\mathrm{Al}$ al-Bayt University-Jordan under the Biological Sciences Department since 2010. He was appointed as the dean assistant for student's affaires (2014-present). He received his BSC in applied biological science at Jordan University of Science and Technology (JUST) in 2007, the master degree in biological sciences at $\mathrm{Al}$ al-Bayt University in 2003 and the doctorate degree in biological science (microbial biotechnology) at USM-Malaysia in 2009.

He worked at ministry of education, Jordan from 1998-2006 as a teacher and the school principal. He published some articles, one of them are cited in this article and the others about bioremoval of heavy metals, Phenol, and dyes.

Dr. Al-Fawwaz is a member of the following societies; Malaysian Society of Applied Biology (MSAB), International Society for Applied Phycology (ISAP) and Asia-Pacific Chemical, Biological \& Environmental Engineering Society (APCBEES). 